\title{
Emphasis on Organoids in Cancer Research
}

\author{
Kartiki Bhandari ${ }^{1}$, Rupali Patil, ${ }^{2, *}$, Prashant Pingale $^{1}$, Sunil Amrutkar ${ }^{3}$ \\ ${ }^{1}$ Department of Pharmaceutics, GES's Sir Dr. M. S. Gosavi College of Pharmaceutical Education and Research, Nasik-422005, \\ Maharashtra, India \\ ${ }^{2}$ Department of Pharmacology, GES's Sir Dr. M. S. Gosavi College of Pharmaceutical Education and Research, Nasik-422005, \\ Maharashtra, India \\ ${ }^{3}$ Department of Pharmaceutical Chemistry, GES's Sir Dr. M. S. Gosavi College of Pharmaceutical Education and Research, \\ Nasik-422005, Maharashtra, India
}

Received April 27, 2021; Revised July 12, 2021; Accepted July 25, 2021

\section{Cite This Paper in the following Citation Styles}

(a): [1] Kartiki Bhandari, Rupali Patil, Prashant Pingale, Sunil Amrutkar, "Emphasis on Organoids in Cancer Research," Cancer and Oncology Research, Vol. 7, No. 2, pp. 11 - 22, 2021. DOI: 10.13189/cor.2021.070201.

(b): Kartiki Bhandari, Rupali Patil, Prashant Pingale, Sunil Amrutkar (2021). Emphasis on Organoids in Cancer Research. Cancer and Oncology Research, 7(2), 11 - 22. DOI: 10.13189/cor.2021.070201.

Copyright $(2021$ by authors, all rights reserved. Authors agree that this article remains permanently open access under the terms of the Creative Commons Attribution License 4.0 International License

\begin{abstract}
Cancer has been one of the deadliest diseases for several decades and there is no precise and standard treatment option available up to date. Statistical data indicate that cancer has been one of the principal reasons for mortality worldwide. Although most of the novel techniques assist in the acceleration of cancer research, the available anticancer therapy does not exhibit expected success rates. This is due to a lack of understanding about the root cause of the disease, which can be accomplished by studying different types of tumors and the effects of various anti-cancer agents on the tumors. These studies require various in vitro study models which can mimic real, in vivo cancers. Conventional experimental models such as animal models, two-dimensional (2D) cell lines, patient-derived xenografts (PDX) are key models in cancer study but they have some shortcomings that are overcome by three-dimensional (3D), in-vitro tumor organoids derived from embryonic, induced pluripotent, or adult stem cells (ESCs, iPSCs, ASCs respectively). These organoid models closely recapitulate the original tumor present in vivo and thereby benefit in studying the development of cancer, efficacy, and safety of various anti-cancer agents, drug development, personalized therapy, low and high throughput screening. As a result, 3D organoids are becoming more successful experimental models over conventional 2D models. Therefore, this review emphasizes the effectiveness of organoid models in cancer study, their method of preparation, advantages and applications, drawbacks with solutions to address, followed by a brief outline on 4D organoids (assembloids),
\end{abstract}

and future perspectives.

Keywords Cancer, Tumor Organoids, 3D Model, Embryonic Stem Cells (ESCs), Induced Pluripotent Stem Cells (iPSCs), Adult Stem Cells (ASCs)

\section{Introduction}

Cancer is a very complicated disorder and the $2^{\text {nd }}$ main cause of mortality globally [1]. There are around 200 different forms of cancer [2]. Cancer is comprised of a variety of heterogeneous and rapidly proliferating cells that emerge in the developing and adaptable microenvironment of the tumor. In recent decades, cancer research and cancer survival rates have greatly improved. Early detection or care, clinical strategies to control and monitor precancerous indications, improved understanding regarding smoking and other wellness behaviors, and therapeutically oriented tumor studies have all contributed to a $26 \%$ decrease in cancer mortality rates over the last two decades. Even after this advancement, cancer remains the leading reason for mortality. Additionally, it is predicted that cancer will remain the primary reason for mortality until 2035, with more than 2 lakh tumor fatalities anticipated in the UK. As we move closer to a cancer cure, it is becoming clear that evidence from several preclinical trials and research work doesn't 
always work out in actual cases. Many conventional methods, such as two-dimensionally cultured cells, explants, organ-on-a-chip systems, and animal testing are critical for studying cancer biology but these models may fail to recapitulate the characteristics of the original tumor. Additionally, novel and creative model systems were found to increase preclinical study translational performance, and hence tumor-derived organoid cultures have emerged as a result, which provides an excellent methodology for designing and studying human cancer [3]. The detection of molecular biomarkers of drug sensitivity is a key step in the rapid production of multiple therapies with particular molecular targets. To find therapeutic biomarkers, tumor models must replicate the original tumor, predict the patient's in vivo treatment response, and be suitable for high-throughput screening [4]. Organoids are in vitro self-developing three-dimensional (3D) tissue recreations developed from embryonic stem cells, induced pluripotent stem cells, or tissue-resident progenitor cells; which mimic primary characteristics i.e., genetic, cellular, and pathophysiological features of the original tissue [5]. Organoids are developed by dissolving tumor biopsies into pieces and cells and incorporating them in an extracellular 3D matrix scaffold (like Matrigel), cultivated in a blend of signaling and growth factors that are specific as well as optimum for each tumor form [6]. This review starts by explaining the pros and cons of the model systems currently being used in tumor research, thereby shifting onto the discussion of tumor cell-derived organoid models, along with their significance in cancer research, and emphasizing its benefits such as possible use in personalized medicinal therapy, drawbacks, and future prospects.

\section{Cancer}

Cancer is defined by the uncontrolled development of abnormal cells due to overproduction and malfunctioning of the body's cells and the acquisition of metastatic properties. In most cases, oncogenes activation and/or deactivation of tumor suppressor genes contribute to unregulated cell cycle development and deactivation of apoptosis pathways further contributing to cancer [7]. Cancer comprises more than 200 different diseases. If we consider the number of cases and death by organ site, disregarding other clinical as well as biological factors, then cancer falls under 3 classes:

Table 1. Classification of various cancers based on incidences \& mortality by organ site [8]

\begin{tabular}{|c|c|c|c|}
\hline $\begin{array}{c}\text { Group 1: Cancer raised from } \\
\text { Epithelia/ Carcinoma: }\end{array}$ & \multicolumn{2}{|c|}{$\begin{array}{l}\text { Cancers that are less } \\
\text { prevalent than group 1: }\end{array}$} & Rare Cancers: \\
\hline Lungs & \multicolumn{2}{|c|}{ Kidney } & Soft tissues \\
\hline $\begin{array}{c}\text { Intestine/ Colorectal (more } \\
\text { common in developed } \\
\text { countries) }\end{array}$ & \multicolumn{2}{|c|}{ Pancreas } & Brain \\
\hline $\begin{array}{c}\text { Breast (in females) } \\
\text { (Common in both developed } \\
\text { \& Developing countries) }\end{array}$ & $\begin{array}{l}\text { Bladder } \\
\text { Stomach } \\
\text { Liver }\end{array}$ & $\begin{array}{l}\text { Endemic in some } \\
\text { countries with } \\
\text { many young } \\
\text { patients }\end{array}$ & Testes \\
\hline Prostate (in males) & \multicolumn{2}{|c|}{ Oesophagus } & Bone \\
\hline $\begin{array}{l}\text { Skin (most prevalent; rarely } \\
\text { lethal, except melanoma) }\end{array}$ & \multicolumn{2}{|c|}{ Cervix } & Other organs \\
\hline & \multicolumn{2}{|c|}{ Ovary (as frequent as leukemia \& lymphoma) } & \\
\hline
\end{tabular}


In the above table, group 1 indicates cancer arising from epithelia also known as carcinoma (cancer of cells which makes up skin or tissue lining) which includes tumors of some major organs like lungs, colorectal or intestinal, rarely lethal skin cancer (except melanoma), breast and prostate. Group 2 summarizes cancers that are less prevalent than group 1 cancers, these include- cancers of kidney, pancreas, stomach, liver, bladder, esophagus, cervix, and ovary. In group 2, ovarian cancer is as frequent as leukemia and lymphoma. Whereas, stomach, bladder, and liver cancers are found to be endemic in some countries with a greater number of young patients. $3^{\text {rd }}$ group is of rare cancers like cancer of soft tissue, brain, testes, bone, and other organs.

Industrialization and smoking are responsible for the increased number of lung, kidney, prostate, testicular, and bladder cancer patients in recent years. Also, melanoma is increasing alarmingly in some areas. On other hand, awareness about hygiene and good food habits is leading to a reduction in the number of stomach cancer patients. Geographical and temporal differences have a large impact and hence it is a prerequisite to study cancer. E.g., prostate cancer in east Asia countries is 10-20 folds lower than in the USA [8]. As per the data obtained from THE
GLOBAL BURDEN OF DISEASE-2004 UPDATE, the death rate by cancer was $11.8 \%$ in females and $13.4 \%$ in males. Cancer was 3rd cause of death amongst all with more incidences and death due to cancers of the bladder, liver, pancreas, corpus uteri, mouth and oropharynx, leukemia, melanoma, and other skin cancers; in both males and females [9]. However, according to GLOBOCAN 2008 statistics, nearly 12.7 million cases of cancer and 7.6 million fatalities by cancer were registered in 2008, with developing countries responsible for $56 \%$ of cases and $64 \%$ of deaths. Breast cancer was the most common cancer in women whereas lung cancer was the more prevalent cancer in men [10]. By the end of 2012, almost 14.1 million new cancer cases were identified with 8.2 million deaths by cancer [11]. The data presented by GLOBOCAN 2020 indicate a rise in the incidence of cancer and deaths from 2020. Globally, an approximate 19.3 million new tumor cases and nearly 10.0 million fatalities by cancer occurred in 2020; in which 1.2 million cases were of melanoma, with 1 lakh deaths by the same. More cases of female breast cancer have been reported, exceeding lung cancer cases. Still, the mortality rate of lung cancer was higher.

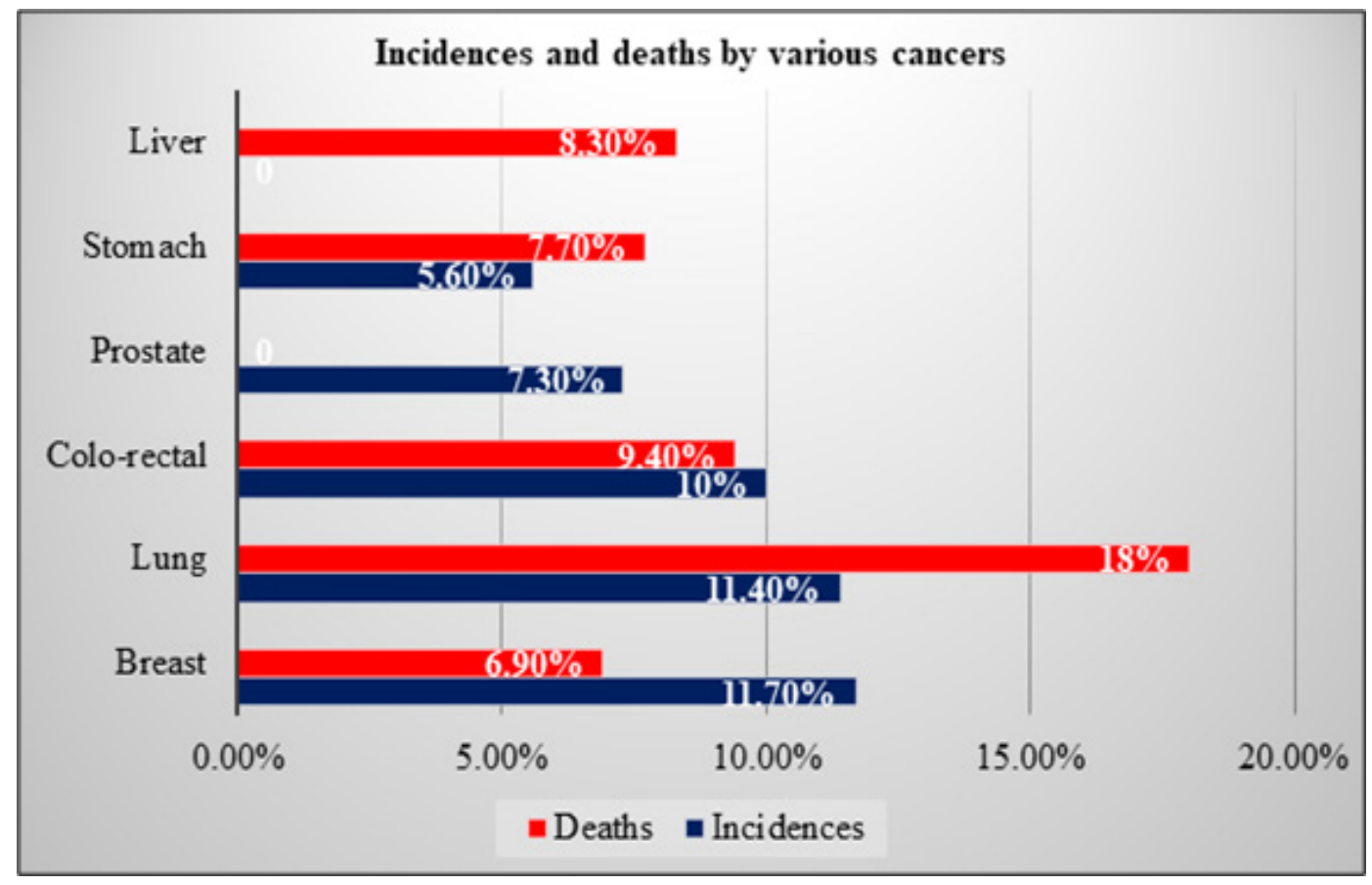

Graph 1. Statistical representation of incidences \& deaths by different types of cancers in 2020 
The above graph shows incidences and mortality by various cancers of some major organs like liver, stomach, prostate, colorectal, lung, and breast cancer. The highest mortality rate and second-highest incidence rate were observed with lung cancer cases. The lowest incidence rate was of stomach cancer. In the case of breast cancer, though the incidence rate was highest, the mortality rate was found to be the lowest.

Owing to population changes the global cancer risk is projected to rise to 28.4 million new cases by 2040 , hence the development of a robust framework for the dissemination of tumor risk reduction strategies as well as the provision of disease care is vital for global cancer prevention [12]. Surgical interventions, chemotherapy, immune therapy, site-directed therapy, stem cell therapy, radiation treatment, hormonal treatment, precision medicines, biomarker testing, oral anticancer medicines, and palliative care are some of the available cancer treatment options, according to NCI (National Cancer Institute) data [13]. The complicated biology of solid tumor growth is one of the main barriers to effective cancer treatment [14]. Cancer is characterized by unusual genetic activity and disturbed genetic expressional habits. According to research, produced genetic defects are linked to genetic mutations that trigger gene deregulation, leading to cancer [15]. Some cancer cells undergo metastasis and spread from the primary tumor site to other organs or throughout the body, leading to additional, unexpected health problems and intensifying complications. This increases patient dependency on drugs, potentially leading to serious side effects and many drugs shows resistance to treatment. Thus, although cancer therapy focuses mainly on the treatment of primary cancer, improving the quality of life with palliative care is equally important and beneficial. The success rate of surgery and radiotherapy is higher for tumors developed in organs. Whereas chemotherapy is usually preferred for advanced cancers, although the success rate is modest with more side effects. Testicular cancers are treated at a rate of more than $90 \%$ with a combination of chemotherapy and radiotherapy. In comparison to this, other cancers have less success rate as the underlying molecular or cellular variations are not apparent [9]. All these indicate that cancer remains one of the deadliest diseases in the world, since conventional anticancer treatments have several shortcomings, as cell biology is not understood well because of the unavailability of suitable experimental systems. Hence there is a need to establish new, universal, and promising anti-cancer strategies for cancer diagnosis and treatment [16].

\section{Material and Methods}

\subsection{Experimental Models:}

Most conventional models which are available to study cancer development and the effect of novel anticancer drugs include; animal models, 2D cell lines, organ-on-a-chip, patient-derived xenografts (PDX), etc.

\subsubsection{Animal model:}

Preclinical animal models are crucial elements of cancer research in which the tumor is induced in genetically modified transgenic mice exposed to carcinogenic chemicals, viruses, or radiation. Despite being a conventional model, animal models are costly. They need substantial investment, yet several successful pre-clinical trials aren't tested actually in humans or aren't suitable for clinical use in drug production. Animals have distinct genomic, physiological, and neurological traits than humans. Often, face ethical constraints due to the use of a live animal.

\subsection{2. $2 \mathrm{D}$ cell lines}

These are either primary cell cultures (cultivated exclusively from the human or animal tumor) or well-established immortalized cell lines. These cell lines are simple to generate at a low cost and are highly reproducible but they grow slowly with a short life span. They lack a microenvironment and are difficult to relate to the original biological tumor. Do not exhibit heterogeneity in the cell and experience unnatural adhesion forces.

\subsubsection{Organ-on-a-chip system}

This is a multiple channeled, microfluidic, perfusion culture of live human tumor cells enclosed with either plastic, glass, or flexible polymers that allow for fairly precise modeling of the organ system's anatomy, but several times it requires cell lines as well. Moreover, this system shows some variation between chips and it is a non-standard protocol.

\subsubsection{Patient-derived or Rodent xenografts}

This approach involves implanting human tumor cell lines or tissues into humanized animals like mice, developing orthotopic (implanted at the location of a body wherein the tumor originated) or heterotopic (implanted somewhere else) xenografts. As the tumor is developed in mice, they lead to ethical constraints and the model works in a non-human environment with a different immune system. Additionally, it is an expensive technique that requires sufficient resources [3].

\subsubsection{Spheroids}

These are simple, in vitro 3D structures produced by a single cell type aggregate. They are difficult to manage for a longer period [17].

\subsubsection{Organoids}

All of the above-mentioned are conventional cancer models and almost all of them have some or other drawbacks that have surpassed by recently established in vitro 3D cell culture technique called "Organoids" that 
resulted in the creation of the innovative and more functional model of normal as well as tumor tissues.

\section{Organoids}

After being incorporated in a 3D framework, adult stem cells developed from tissues may grow into self-organizing organotypic structures with high efficiency, called "organoids" that can recapitulate the tissue or organ of origin. In the year 2009, it was proven [18] that 3D epithelial cell organoids can be developed by intestinal stem cell with only one repeat that is rich in leucine and contains $\mathrm{G}$ protein-coupled receptor 5 (LGR5)+. [19] Although 3D tissue culture has been around for decades, the term organoid is now more widely utilized to define stem cell-derived models wherein cells can be pluripotent stem cells (PSC), such as embryonic stem cells (ESC) or induced pluripotent stem cells (iPSC), or can be adult stem cells (ASC) from specific organs [20].

\subsection{Method of Preparation of 3D and 4D Organoids}

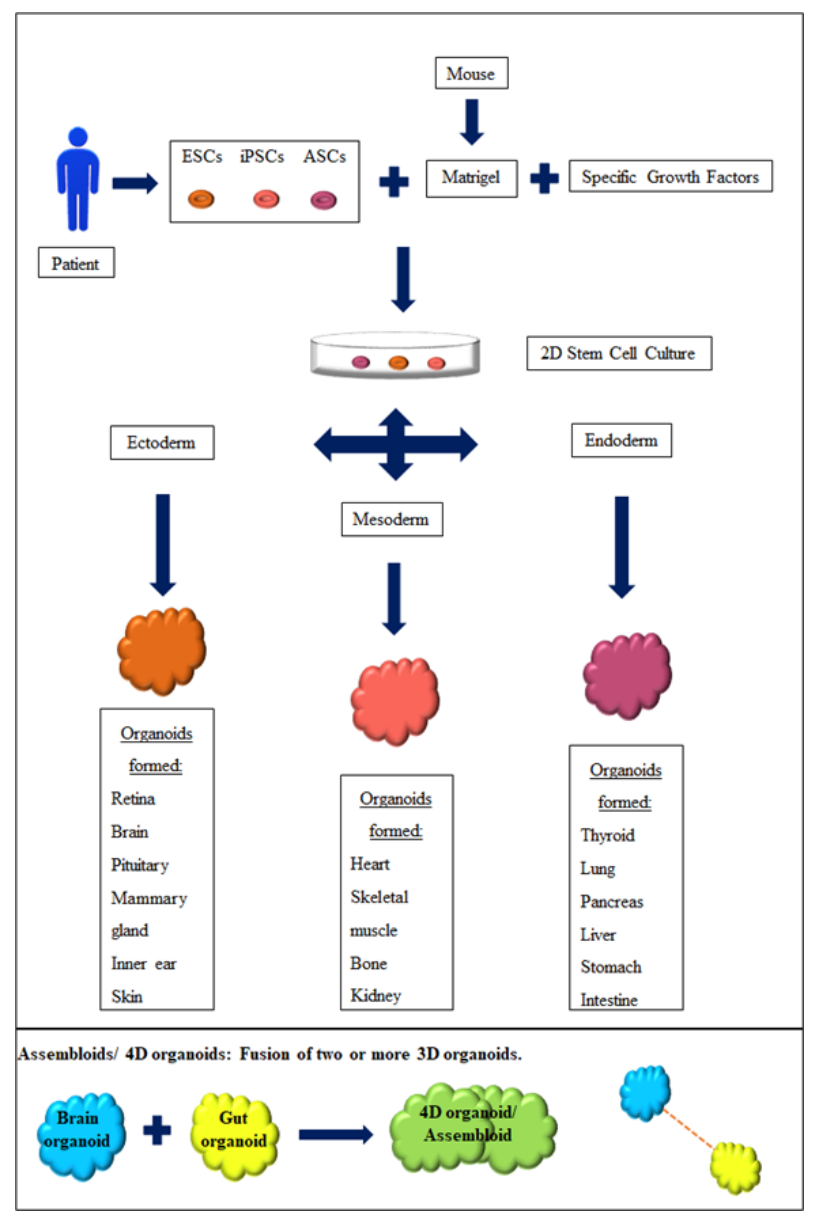

Figure 1. The process of preparing 3D organoids and 4D assembloids. $[21,22]$

Matrigel is a gelatinous protein mixture originating from mouse cancer cells that are used as a basement membrane matrix of stem cells to keep them undifferentiated [23]. Stem cells proliferate further to form ectoderm, mesoderm, and endoderm, which results in the development of organ-specific organoids. Drugs can be tested directly on these organoids, or organoids can be transplanted into mice to check the effectiveness of anti-cancer drugs. Fusion of two or more 3D organoids forms $4 \mathrm{D}$ organoids/ assembloids. The interesting part is that co-culturing of brain organoids with any other organ-derived organoids leads to the formation of assembloids in which derived organs may receive signals from brain organoids formed in vitro.

The diagram represents the process of preparation of 3D and 4D organoids in vitro. Embryonic, induced, or adult stem cells are taken from cancer patients and cultivated in Matrigel with specific growth promotors.

\subsection{Cultural Components Required for Growth of Various Tumor Organoids:}

\subsubsection{Extracellular matrix (ECM):}

Matrigel is used for pancreatic and bladder cancer. Matrigel (reduced growth factor) is used for stomach, intestine, and prostate cancer. Basement membrane extract for liver and Basement membrane extract (reduced growth factor) for breast cancer.

\subsubsection{Molecular inhibitors:}

A-83-01 used for all above cancers (except bladder cancer). Y27632 is used for all the above cancers (except pancreatic and prostate cancer). SB202190 is used for stomach, intestine, and prostate cancer.

\subsubsection{Growth factors:}

ADMEM/F12, Noggin, R-spondin-1, and penicillin/streptomycin are used for all cancer cultures. Gastrin and Wnt3A present in all (except breast and prostate organoids). N-acetylcysteine present in all cancer organoids (except stomach, intestine), and nicotinamide present in all cancers (except pancreatic). GlutaMAX present in all (except stomach and intestine). Prostaglandin E2 present in organoids of the stomach, intestine, and prostate. L- glutamine and bovine serum albumin used for the stomach and intestine. B27 and FGF are used in all (except bladder cancer). N2 is used for stomach, intestine, and liver organoids. EGF is used for all (except breast cancer). HEPES used in liver, pancreatic, and breast cancer. HGF and forskolin are used only for the intestine. Primocin for breast, bladder, and prostate. Testosterone, FBS, and neuregulin1 are used for prostate, bladder, and breast cancers respectively. Isolation medium definite for hepatic tumor organoid includes standard human hepatic organoid isolation media with the incorporation of dexamethasone and the exclusion of R-spondin-1, Wnt3A, and Noggin. Standard human 
hepatic organoid isolation media with the exclusion of Y27632, Wnt3A, and Noggin for normal human hepatic tumor organoids [44]. Some techniques to develop pluripotent stem cell-derived organoids provide nominal differentiation information to the cells (without supplying sufficient growth promotors and nutrients), permitting inherent self-organization. E.g., Matrigel trapped neuroectodermal embryoid bodies from hPSC + no other precise conditions provided to the cells $=$ generates brain organoids with several brain areas, including cortex, but also generates some endodermal and mesodermal ancestries. Whereas, in another method, cells are structured into more complex regions of the CNS, which usually depends on prior knowledge of the signals that regulate growth, with additional contributions from self-organizing methods. E.g., Matrigel trapped hPSC + dorsal or ventral forebrain structures $=$ formation of region-specific brain organoids. Development factors for adult stem cell-derived organoids are normally similar to signals that regulate tissue recovery after injury or steady-state tissue maintenance in the body. As a result, agonists of Wnt signaling are required to maintain the cells and produce an in vivo-like complement of cell types in adult stem cells-derived epithelial cell organoids in the multiple organs in GIT [20].

\section{Discussion and Result}

\subsection{Examples of Available Organoid Models:}

To examine the impact of anti-cancer as well as other drugs, various $3 \mathrm{D}$, self-originating organoids are obtained from all the organs mentioned in Figure 1. Such as-

mESCs derived Thyroid organoid [24]

Adult mouse's lung stem cells derived bronchioalveolar systems [25]

Organoids of the pancreas derived from embryonic pancreatic progenitor cells in mouse [26]

Hepatic organoids derived from adult stem cells [27]; liver buds derived from human iPSCs [28]

Adult stem cell-derived gut organoids [29, 30]

Human PSC-derived intestinal organoids [31]

hESC-derived cardiovascular patch [32]

A three-dimensional matrix obtained from myoblast progenitors anchors contracting skeletal muscle [33]

Human osteogenic cell-derived osteo spheroids [34]

Organoids of the kidney derived from mice and human PSCs include the uterine bud as well as metanephric mesenchyme [35-37]

Human and mice PSCs' derived optic cups organoids $[38,39]$ [40]

Human and mouse PSCs derived Organoids of the brain

Organoids of the adenohypophysis derived from mice PSCs [5]
Matrigel-embedded 3D breast epithelia [41]

mESC-derived inner ear organoids [42]

mESC-derived keratinocyte-derived stratified epidermal layer [43]

\subsection{The Success Rate of Cancer-Derived Organoids}

The graph shows the success rate or efficiency of available 3D organoids models in different types of cancer studies, with the number of organoids varying depending on the type of cancer being studied. Severe tumor indicates metastatic, circulating, combined hepatocellular-cholangiocarcinoma, high-grade serous carcinoma of the ovary, mixed carcinomas such as metastatic colorectal and gastrointestinal carcinoma in multiple cancer forms, whereas primary tumor indicates basic tumors. The success rate was found to be $>80 \%$ for ovary, primary colorectal, metastatic liver, and rectal organoids. Whereas, lowest $(<20 \%)$ success rate was observed in prostate organoids.

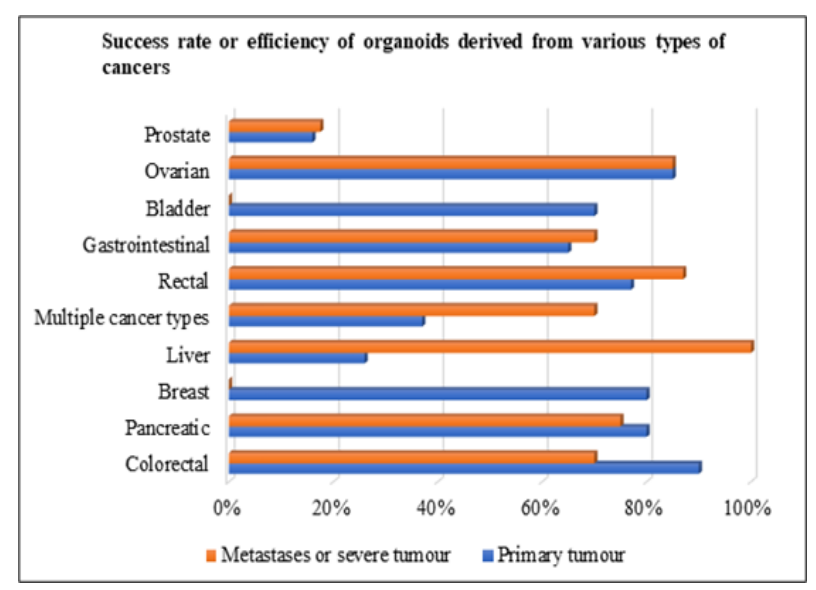

Graph 2: The success rate or efficiency of available 3D organoids models in different types of cancer studies. [27, 45-60]

\subsection{Comparison of Organoids with Traditional Cancer Study Models}

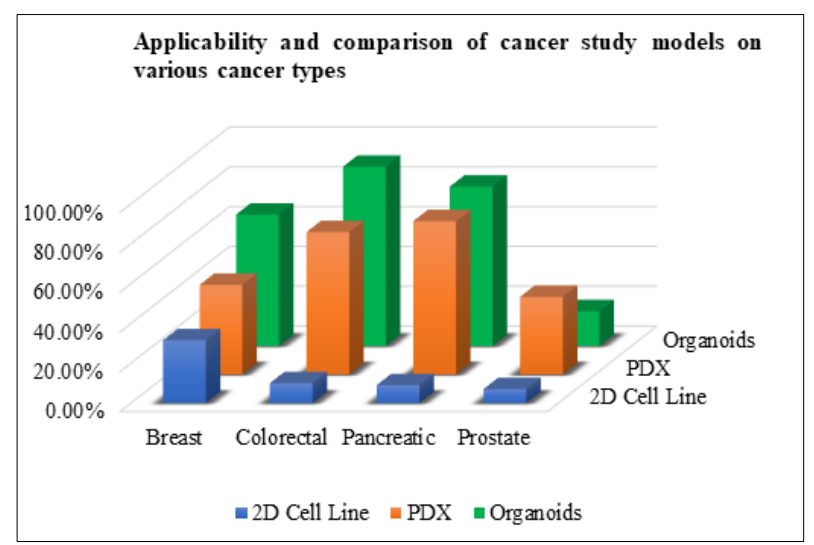

Graph 3: The success rates of various cancer study models [61-64] 
The graph explains the success rates of various cancer study models namely; 2D cell lines, patient-derived xenografts (PDX), and organoids in four major cancer types namely- breast, colorectal, pancreatic, and prostate cancer. The graph indicates that the success rate of organoids is greater than that of conventional study models used for cancer research like 2D cell lines or PDX and hence it's becoming a more reliable cancer study model over other traditional study models

Comparison between 2D experimental models with the novel 3D organoid approach: The table compares traditional 2D experimental models such as $2 \mathrm{D} / 3 \mathrm{D}$ cell lines and animal models such as a genetically engineered mouse (GEM) and patient-derived xenografts (PDX) with a novel 3D organoid approach such as cancer stem-like cell (CSC) derived organoids and cancer tissue-originated spheroids (CTOS), in terms of accessibility, feasibility, inter-tumor heterogeneity, intra-tumor heterogeneity, physiological features and application to high throughput screening (HTS).

\section{Advantages}

Adult stem cells can be studied by cultivating in organoids, and unique tissue lineages can be developed with limited input from other cell types in good purity (e.g., endothelial cells and fibroblasts).

Can also be generated for years without causing genetic changes.

Allows for the use of a broad range of proven methodological approaches.

Possible to extract with several initial sources, including adult as well as fetal tissues, ESCs, and iPSCs.

Organoids covering a wide spectrum of tissues can be produced.

Restricted quantities of precursor materials may be extended for several applications.

Patient-derived organoids can be used to study human disorders which are hard to analyze in animals, also avoid extensive animal studies.

It is possible to generate isogenic adult tissue for use in regenerative operations [66].

Table 2. Comparison between 2D experimental models with novel 3D organoid approach [65]

\begin{tabular}{|c|c|c|c|c|c|c|c|}
\hline \multicolumn{2}{|c|}{ Model Name } & \multirow{2}{*}{$\begin{array}{c}\text { Accessibility } \\
\text { Good }\end{array}$} & \multirow{2}{*}{$\begin{array}{c}\text { Feasibility } \\
\text { Good }\end{array}$} & \multirow{2}{*}{$\begin{array}{c}\begin{array}{c}\text { Inter-tumor } \\
\text { Hetero- } \\
\text { geneity }\end{array} \\
\text { Can compare } \\
\text { between cell } \\
\text { lines } \\
\end{array}$} & \multirow{2}{*}{$\begin{array}{c}\begin{array}{c}\text { Intra-tumor } \\
\text { Heterogeneity }\end{array} \\
\text { Low }\end{array}$} & \multirow{2}{*}{$\begin{array}{c}\text { Physiological } \\
\text { Features }\end{array}$} & \multirow{2}{*}{$\begin{array}{c}\begin{array}{c}\text { Applicability } \\
\text { to HTS }\end{array} \\
\text { Good }\end{array}$} \\
\hline & $2 \mathrm{D}$ & & & & & & \\
\hline Cell lines & $3 \mathrm{D}$ & Good & $\begin{array}{l}\text { Complicated } \\
\text { for some } \\
\text { systems having } \\
\text { biomaterials }\end{array}$ & $\begin{array}{l}\text { Can compare } \\
\text { between cell } \\
\text { lines }\end{array}$ & Low & $\begin{array}{c}\text { Partially } \\
\text { re-established }\end{array}$ & $\begin{array}{c}\text { Tough with } \\
\text { some cell lines }\end{array}$ \\
\hline & GEM & $\begin{array}{l}\text { Relatively } \\
\text { good once } \\
\text { established }\end{array}$ & $\begin{array}{c}\text { Intricate in case } \\
\text { of double/triple } \\
\text { GEMs }\end{array}$ & $\begin{array}{l}\text { Can compare } \\
\text { partially }\end{array}$ & High & $\begin{array}{l}\text { Well established \& } \\
\text { includes immune } \\
\text { system \& } \\
\text { micro-environment }\end{array}$ & Unfit for HTS \\
\hline $\begin{array}{l}\text { Animal } \\
\text { models }\end{array}$ & PDX & $\begin{array}{l}\text { Access to } \\
\text { tissue } \\
\text { network or } \\
\text { hospital is } \\
\text { desired }\end{array}$ & $\begin{array}{l}\text { Good once } \\
\text { generated }\end{array}$ & $\begin{array}{c}\text { Can compare } \\
\text { between } \\
\text { multiple cases }\end{array}$ & High & $\begin{array}{l}\text { Good, including } \\
\text { micro-environment }\end{array}$ & Unfit for HTS \\
\hline \multirow[t]{2}{*}{ Organoids } & $\begin{array}{l}\text { CSC-derived } \\
\text { organoid }\end{array}$ & $\begin{array}{l}\text { Access to } \\
\text { tissue } \\
\text { network or } \\
\text { hospital is } \\
\text { desired }\end{array}$ & $\begin{array}{c}\text { Skills required, } \\
\text { may lead to the } \\
\text { low recovery } \\
\text { rate }\end{array}$ & $\begin{array}{c}\text { Can compare } \\
\text { between } \\
\text { multiple cases }\end{array}$ & High & Well established & $\begin{array}{l}\text { Possible but } \\
\text { costly }\end{array}$ \\
\hline & CTOS & $\begin{array}{l}\text { Access to } \\
\text { tissue } \\
\text { network or } \\
\text { hospital is } \\
\text { desired }\end{array}$ & $\begin{array}{l}\text { Skills are } \\
\text { necessary }\end{array}$ & $\begin{array}{c}\text { Can compare } \\
\text { between } \\
\text { multiple cases }\end{array}$ & High & Well established & $\begin{array}{c}\text { Good } \\
\text { applicability as } \\
\text { an ex vivo } \\
\text { setting }\end{array}$ \\
\hline
\end{tabular}




\section{Drawbacks and Solutions to overcome some drawbacks:}

More complex than 2D cell lines, thereby likely to show more variations which can occur between different initiating cell lines or genotypes, but also between batches of organoids from the same initial components, between multiple organoids within the same culture, or even between different sites of a single organoid. Organoids also vary significantly in their capability to segregate in specific categories of cells.

An absence of vasculature and immune system due to lack of nutrients limits their growth without cell death, and they cannot be utilized in studies involving vasculature and the immune system. Vascularization can be resolved by the use of spinning bioreactors for better nutrient exchange or by co-culturing with endothelial cells as well. The introduction of hybrid cultures in organoids is also possible to form a more reliable organoid culture with various cell types [67]. Also, limited stromal and immune components hamper the use of organoids in the study of inflammation and drug penetration [66, 68].

The absence of an original microenvironment as in vivo limits the interactions of stem cells with their niches, immune cells, etc. Also, the Prediction of inflammatory reactions to infection or therapeutic agents is difficult due to a lack of immune system. This can be prevented by the use of organotypic cultures, or co-culturing with other cell types like stromal cells [69] or immune cells.

The Matrigel matrix was insufficient to replicate in vivo growth factor gradients. So, we can apply a microfluidic technique that will create concentration gradients thereby overcoming this issue.

The inability to reproduce actual biomechanical conditions encountered by cells in the body can be recovered by the use of novel substrates and ECM factors to generate such interactions in vitro [70-72].

The utilization of organoids in drug evaluations can be hampered if the ECM is comparatively rigid. It is difficult to grow organoids from tissues whose niche factors are unknown (such as, the ovary). In such cases, we need to alter the physical properties of ECM such as composition, porousness, and rigidness or we can screen for small-molecule modulators of major signaling pathways and specific hormones as potential components in culture.

Organoids in a similar culture vary in respect of viability, shape, and size, making phenotype screening difficult, that's why live or time-lapse imaging is used to track organoids individually.

Organoid cultures rely on Matrigel originating from mouse sarcomas, which may show variations after implantation of organoids into humans. To compensate for this, better-defined ECMs which will promote organoid development are being used.

\section{Applications:}

Organoids have made it possible to reproduce human tumors in vitro in a way that has never been achieved before. Organoids obtained from various animal or human cancers are now extensively used in the research of various cancers. Various organ-specific organoids are established in recent decades such as; a) Organoids of CRC (Colorectal Cancer) from various anatomical locations with changing sensitivity to Wnt3a and R-spondin proteins. b) Hepatic cancer organoids were extracted from patients through comprehensive medium refining to extend the 3 main subcategories: liver cell carcinoma, cholangiocarcinoma, and combined liver cell-cholangiocarcinoma. c) Enduring preservation and enhancement of pancreatic ductal adenocarcinoma (PDAC) organoids derived from human and animal prime cells maintaining the primary tumor's architecture and phenotypic heterogeneity. d) Primary breast cancer organoids closely resemble their original tumors, in terms of anatomy, pathology, hormonal receptor interaction, and mutation site. e) Some more tumor organoids, such as those for gastric, prostate, ovarian, brain, bladder, kidney, lung, and oesophageal cancers are also developed.

Human cancer can also be designed by introducing pathological mutations to wild-type organoids through gene editing techniques like transmission of genes, CRISPR-Cas9, or RNA interferences. For example, colorectal adenoma-carcinoma sequences can be reconstructed by introducing driver mutations (APC, KRAS, TP53, SMAD4, and PIK3CA) into stable wild-type organoids, which then develop into invasive cancer upon implantation. After further examination of various APC truncating mutations in intestinal organoids, the critical functional area for pathological Wnt stimulation in CRCs was discovered.

Seino and colleagues used CRISPR-targeting to develop cancer driver genes SMAD4, CDKN2A, TP53, and KRAS, in PDAC organoids, revealing an unforeseen Wnt niche adaptive behavior triggered by TP53 mutations.

Cancer-derived organoids usually sustain tumor heterogeneity, making them perfect for research on tumor growth. Organoids originating from predominant colorectal tumors and metastatic tumors isolated from the same patient expressed similar common sources and driver mutation, implying that the driver mutations happen before metastatic spread. For evaluation of diversities within the tumor, researchers generated clonal organoids from many individual cells from $3 \mathrm{CRCs}$ as well as adjacent natural intestinal crypts. The global mutational landscape had been utilized for building phylogenetic trees, revealing that $\mathrm{CRC}$ cells have substantial mutational diversification and that the majority of mutations occurred during cancer's final predominant clonal expansion. When these three-dimensional organoids are integrated, they provide ground-breaking in vitro methods of development of cancer models, phylogenetic analysis, and clinical research in new drug development [73].

Future prospects: 
In a large number of COVID-19 patients, researchers investigated SARS-CoV-2 neurotropism in single-layer neuronal cells and human pluripotent stem cells (hPSC) developed brain organoids, finding that this virus infects only the choroid plexus, causing apoptosis and transcriptional up-regulation of inflammatory genes, as well as functional impairment in the neuronal cells [74]. Several unresolved issues can be answered by hPSC-based models, like the accurate action of this virus on nerve cells, the actual mechanism behind differential viral vulnerability (such as activation of particular coreceptors in virus by dopaminergic neurons against cortical neurons) if COVID-19 infection can cause long-term nerve damage, as well as the recognition of the virus. The first research with primary organoids developed from human cells was already released to recognize therapeutic agents which may relieve other diseases caused following COVID-19 infection [75, 76], and it will be interesting to know if impacts found in this research can be transferred to a clinical surrounding [77].

The latest evidence has shown that cerebral organoids based on human neural stem cells can be successfully transplanted into mice brains and display improved integration, differentiation, and maturation $[78,79]$. The discovery of synaptic communication between the graft and host neuron by the dissemination of axonal projections of humans in the brain of a mouse was an unexpected result. The question is whether or not these mice have been "humanized," and if it is true then can "human" thinking capacity and feelings will emerge in those mice?

From the above observations, it is clear that if $3 \mathrm{D}$ or $4 \mathrm{D}$ brain organoids begin experiencing conscious behavioral symptoms using current medical concepts, it would be important to develop forward-thinking ideas and guidance in the future.

\section{Conclusions}

This review emphasizes the utilization of 3D organoids as an experimental model of cancer research. According to statistics, cancer is now a non-curable disease that affects millions of people worldwide, with a substantial rise in morbidity and mortality. The data show that traditional anti-cancer treatments have failed due to a lack of information about the underlying etiology of cancer and the rapid growth rate of tumor cells. Conventional anti-cancer treatments are still used around the world, but they cause more severe side effects rather than curing cancer, so cancer treatment focuses more on palliative care. Though palliative care is useful, it cannot be used as a primary treatment or as a long-term cure for cancer, so standard therapy for all different cancers is needed. This is only possible after thorough research into cancer models including the study of growth, anatomy, and pathology of cancer cells, apoptosis, the effect of various anti-cancer agents on tumor cells, treatment resistance, and so on. Traditional 2D models are useful for carrying out all of these experiments, but they have certain drawbacks that 3D organoid models overcome. Organoids are in vitro, 3D models that precisely replicate the original human tumor; therefore, all experiments with a higher success rate on organoid systems can be applied to original tumor cells in vivo. These 3D models are made from embryonic or induced pluripotent stem cells (ESCs or iPSCs) as well as adult stem cells (ASCs). Matrigel and specific growth factors are used to build stem cell cultures, which then proliferate to produce organ-specific tissue and, as a result, organ-specific organoids. Organoids are complex models with a higher success rate than other 2D models, and they are well suited for low and high throughput screening [80]. Organ-specific organoids are developed which have the significant ability to develop in vitro and mimic real tumors. They have several applications, including examining the effectiveness and safety of new or existing anticancer and other drugs, developing precision medicine [81], to build 4D organoids in vitro by fusion of two or more 3D organoids [82]. A link between two separate organ-derived organoids can be established using this process. Despite some disadvantages due to complex modeling, organoids remain the most effective model of all and serve as a boon in cancer research.

\section{REFERENCES}

[1] Zhang M, Vandana JJ, Lacko L, Chen S. Modeling cancer progression using human pluripotent stem cell-derived cells and organoids. Stem Cell Res [Internet]. 2020;49:102063. Available from: https://doi.org/10.1016/j.scr.2020.102063

[2] Press D.

IJN-16923-new-generation-of-cancer-treatment--carbon-na notubes-with-fl. 2011;2963-79.

[3] Porter RJ, Murray GI, McLean MH. Current concepts in tumor-derived organoids. $\mathrm{Br} \mathrm{J}$ Cancer [Internet]. 2020;123(8):1209-18. Available from: http://dx.doi.org/10.1038/s41416-020-0993-5

[4] Gao D, Chen Y. Organoid development in cancer genome discovery. Curr Opin Genet Dev [Internet]. 2015;30:42-8. Available

http://dx.doi.org/10.1016/j.gde.2015.02.007 from:

[5] Clevers H. Modeling Development and Disease with Organoids. Cell [Internet]. 2016;165(7):1586-97. Available from: http://dx.doi.org/10.1016/j.cell.2016.05.082

[6] Maenhoudt N, Defraye C, Boretto M, Jan Z, Heremans R, Boeckx B, et al. Developing Organoids from Ovarian Cancer as Experimental and Preclinical Models. Stem Cell Reports [Internet]. 2020;14(4):717-29. Available from: https://doi.org/10.1016/j.stemcr.2020.03.004

[7] Sarkar S, Horn G, Moulton K, Oza A, Byler S, Kokolus S, 
et al. Cancer development, progression, and therapy: An epigenetic overview. Int J Mol Sci. 2013;14(10):21087113.

[8] Schulz WA. Molecular biology of human cancers: An advanced student's textbook [Internet]. Molecular Biology of Human Cancers: An Advanced Student's Textbook. 2005 [cited 2021 Mar 12]. 1-508 p. Available from https://books.google.com/books?hl=enandlr=andid=Lvkb$\mathrm{XZkqPoCandoi}=$ fndandpg $=$ PR12anddq $=$ Schulz + W. + Mole cular+biology + of + human+cancers: + an + advanced + student $\% 27 \mathrm{~s}+$ textbook. + Springer + Science $+\% 26+$ Business + Medi $\mathrm{a} \% 3 \mathrm{~B}+2005+\mathrm{Feb}+9 .+$ andots $=$ IdjAHvP9PFandsig $=0 \_$h-bm UCylLaJf6zKzxcUugHq_0

[9] Mathers C, Ties B MFD. The global burden of disease 2004. Update World Heal Organ. 2004;146.

[10] Jemal A, Bray F, Ferlay J. Global Cancer Statistics: 2011. CA Cancer J Clin [Internet]. 1999;49 (2):1,33-64. Available from:

http://www.ncbi.nlm.nih.gov/entrez/query.fcgi?cmd=Retri eveanddb $=$ PubMedanddopt $=$ Citationandlist uids $=1020077$ 6

[11] Jung KW, Won YJ, Oh CM, Kong HJ, Lee DH, Lee KH, et al. Cancer statistics in Korea: Incidence, mortality, survival, and prevalence in 2014. Cancer Res Treat. 2017;49 (2):292-305.

[12] Sung H, Ferlay J, Siegel RL, Laversanne M, Soerjomataram I, Jemal A, et al. Global cancer statistics 2020: GLOBOCAN estimates of incidence and mortality worldwide for 36 cancers in 185 countries. CA Cancer J Clin [Internet]. 2021 Feb 4 [cited 2021 Mar 12]; caac. 21660. Available https://onlinelibrary.wiley.com/doi/10.3322/caac.21660

[13] National Cancer Institute. Types of Cancer Treatment National Cancer Institute [Internet]. National Cancer Institute. 2015. p. 368. Available from: https://www.cancer.gov/about-cancer/treatment/types

[14] Izumi H, Torigoe $\mathrm{T}$, Ishiguchi $\mathrm{H}$, Uramoto $\mathrm{H}$, Yoshida $\mathrm{Y}$, Tanabe $\mathrm{M}$, et al. Cellular $\mathrm{pH}$ regulators: Potentially promising molecular targets for cancer chemotherapy. Cancer Treat Rev. 2003;29 (6):541-9.

[15] Jones PA, Baylin SB. The Epigenomics of Cancer. Cell. 2007;128(4):683-92.

[16] Sharma H, Mishra PK, Talegaonkar S, Vaidya B. Metal nanoparticles: A theranostic nanotool against cancer. Drug Discov Today [Internet]. 2015;20 (9):1143-51. Available from: http://dx.doi.org/10.1016/j.drudis.2015.05.009

[17] Pal R. How are Organoids Different from Spheroids? [Internet]. Crownbio Blog. 2019 [cited 2021 Mar 13]. p. 112. Available from: https://blog.crownbio.com/organoids-or-spheroids

[18] Sato T, Vries RG, Snippert HJ, Van De Wetering M, Barker N, Stange DE, et al. Single Lgr5 stem cells build crypt-villus structures in vitro without a mesenchymal niche. Nature [Internet]. 2009;459 (7244):262-5. Available from: http://dx.doi.org/10.1038/nature07935

[19] Drost J, Clevers H. Organoids in cancer research. Nat Rev Cancer [Internet]. 2018;18 (7):407-18. Available from: http://dx.doi.org/10.1038/s41568-018-0007-6
[20] De Souza N. Organoids. Nat Methods. 2018;15(1):23.

[21] Lancaster MA, Knoblich JA. Organogenesis in a dish: Modeling development and disease using organoid technologies. Science (80- ). 2014;345(6194).

[22] Bitar M, Barry G. Building a Human Brain for Research. Front Mol Neurosci. 2020;13(February):1-5.

[23] Hughes CS, Postovit LM, Lajoie GA. Matrigel: a complex protein mixture required for optimal growth of cell culture. Proteomics. 2010;10(9):1886-90.

[24] Antonica F, Kasprzyk DF, Opitz R, Iacovino M, Liao XH, Dumitrescu AM, et al. Generation of functional thyroid from embryonic stem cells. Nature [Internet]. 2012;491 (7422):66-71. Available from: http://dx.doi.org/10.1038/nature11525

[25] Lee JH, Bhang DH, Beede A, Huang TL, Stripp BR, Bloch $\mathrm{KD}$, et al. Lung stem cell differentiation in mice directed by endothelial cells via a BMP4-NFATc1-thrombospondin-1 axis. Cell [Internet]. 2014;156 (3):440-55. Available from: http://dx.doi.org/10.1016/j.cell.2013.12.039

[26] Greggio C, De Franceschi F, Figueiredo-Larsen M, Gobaa $\mathrm{S}$, Ranga A, Semb $\mathrm{H}$, et al. Artificial three-dimensional niches deconstruct pancreas development in vitro. Dev. 2013;140(21):4452-62.

[27] Boj SF, Hwang C Il, Baker LA, Chio IIC, Engle DD, Corbo $\mathrm{V}$, et al. Organoid models of human and mouse ductal pancreatic cancer. Cell. 2015;160 (1-2):324-38.

[28] Takebe T, Sekine K, Enomura M, Koike H, Kimura M, Ogaeri T, et al. Vascularized and functional human liver from an iPSC-derived organ bud transplant. Nature [Internet]. 2013;499 (7459):481-4. Available from: http://dx.doi.org/10.1038/nature12271

[29] Stange DE, Koo BK, Huch M, Sibbel G, Basak O, Lyubimova A, et al. XDifferentiated Troy+ chief cells act as reserve stem cells to generate all lineages of the stomach epithelium. Cell [Internet]. 2013;155 (2):357. Available from: http://dx.doi.org/10.1016/j.cell.2013.09.008

[30] Barker N, Huch M, Kujala P, van de Wetering M, Snippert HJ, van Es JH, et al. Lgr5+ve Stem Cells Drive Self-Renewal in the Stomach and Build Long-Lived Gastric Units In Vitro. Cell Stem Cell [Internet]. 2010;6(1):25-36. Available

http://dx.doi.org/10.1016/j.stem.2009.11.013

[31] Spence JR, Mayhew CN, Rankin SA, Kuhar MF, Vallance JE, Tolle K, et al. Directed differentiation of human pluripotent stem cells into intestinal tissue in vitro. Nature [Internet]. 2011;470 (7332):105-10. Available from: http://dx.doi.org/10.1038/nature09691

[32] Stevens KR, Kreutziger KL, Dupras SK, Korte FS, Regnier $\mathrm{M}$, Muskheli V, et al. Physiological function and transplantation of scaffold-free and vascularized human cardiac muscle tissue. Proc Natl Acad Sci U S A. 2009;106 (39):16568-73.

[33] van der Schaft DWJ, van Spreeuwel ACC, Boonen KJM, Langelaan MLP, Bouten CVC, Baaijens FPT. Engineering skeletal muscle tissues from murine myoblast progenitor cells and application of electrical stimulation. J Vis Exp. 2013; (73). 
[34] Kale S, Biermann S, Edwards C, Tarnowski C, Morris M, Long MW. Three-dimensional cellular development is essential for the ex vivo formation of human bone. Nat Biotechnol. 2000;18 (9):954-8.

[35] Xia Y, Nivet E, Sancho-Martinez I, Gallegos T, Suzuki K, Okamura D, et al. Directed Differentiation of Human Pluripotent Cells to Ureteric Bud Kidney Progenitor-Like Cells. Nat Cell Biol [Internet]. 2013;15 (12):1507-15. Available from: http://dx.doi.org/10.1038/ncb2872

[36] Taguchi A, Kaku Y, Ohmori T, Sharmin S, Ogawa M, Sasaki H, et al. Redefining the in vivo origin of metanephric nephron progenitors enables generation of complex kidney structures from pluripotent stem cells. Cell Stem Cell [Internet]. 2014;14(1):53-67. Available from: http://dx.doi.org/10.1016/j.stem.2013.11.010

[37] Takasato M, Er PX, Becroft M, Vanslambrouck JM, Stanley EG, Elefanty AG, et al. Directing human embryonic stem cell differentiation towards a renal lineage generates a self-organizing kidney. Nat Cell Biol. 2014;16 (1):118-26.

[38] Eiraku M, Takata N, Ishibashi H, Kawada M, Sakakura E, Okuda S, et al. Self-organizing optic-cup morphogenesis in three-dimensional culture. Nature [Internet]. 2011;472 (7341):51-8. Available from: http://dx.doi.org/10.1038/nature09941

[39] Nakano T, Ando S, Takata N, Kawada M, Muguruma K, Sekiguchi K, et al. Self-formation of optic cups and storable stratified neural retina from human ESCs. Cell Stem Cell [Internet]. 2012;10 (6):771-85. Available from: http://dx.doi.org/10.1016/j.stem.2012.05.009

[40] Bershteyn M, Kriegstein AR. Cerebral organoids in a dish: Progress and prospects. Vol. 155, Cell. Cell Press; 2013. p. 19.

[41] Li L, Lu Y. Optimizing a 3D culture system to study the interaction between epithelial breast cancer and its surrounding fibroblasts. J Cancer. 2011;2 (1):458-66.

[42] Longworth-Mills E, Koehler KR, Hashino E. Generating inner ear organoids from mouse embryonic stem cells. Methods Mol Biol. 2016;1341:391-406.

[43] Ikuta S, Sekino N, Hara T, Saito Y, Chida K. Mouse epidermal keratinocytes in three-dimensional organotypic coculture with dermal fibroblasts form a stratified sheet resembling skin. Biosci Biotechnol Biochem. 2006;70 (11):2669-75

[44] Xu H, Lyu X, Yi M, Zhao W, Song Y, Wu K. Organoid technology and applications in cancer research. J Hematol Oncol. 2018;11 (1):1-15.

[45] Wimmer RA, Leopoldi A, Aichinger M, Wick N, Hantusch B, Novatchkova M, et al. Human blood vessel organoids as a model of diabetic vasculopathy. Nature [Internet]. 2019;565 (7740):505-10. Available from: http://dx.doi.org/10.1038/s41586-018-0858-8

[46] Xiang Y, Tanaka Y, Patterson B, Kang YJ, Govindaiah G, Roselaar N, et al. Fusion of Regionally Specified hPSC-Derived Organoids Models Human Brain Development and Interneuron Migration. Cell Stem Cell [Internet]. 2017;21 (3):383-398.e7. Available from: http://dx.doi.org/10.1016/j.stem.2017.07.007
[47] Sarkar A, Mei A, Paquola ACM, Stern S, Bardy C, Klug JR, et al. Efficient Generation of CA3 Neurons from Human Pluripotent Stem Cells Enables Modeling of Hippocampal Connectivity In Vitro. Cell Stem Cell [Internet]. 2018;22 (5):684-697.e9. Available from: https://doi.org/10.1016/j.stem.2018.04.009

[48] Li X, Nadauld L, Ootani A, Corney DC, Pai RK, Gevaert O, et al. Oncogenic transformation of diverse gastrointestinal tissues in primary organoid culture. Nat Med [Internet]. 2014;20 (7):769-77. Available from: http://dx.doi.org/10.1038/nm.3585

[49] Birey F, Andersen J, Makinson CD, Islam S, Wei W, Huber $\mathrm{N}$, et al. Assembly of functionally integrated human forebrain spheroids. Nature. 2017;545 (7652):54-9.

[50] McMurtrey RJ. Analytic models of oxygen and nutrient diffusion, metabolism dynamics, and architecture optimization in three-dimensional tissue constructs with applications and insights in cerebral organoids. Tissue Eng Part C Methods [Internet]. 2016 Mar 1 [cited 2021 Mar 14];22 (3):221-49. Available from: https://www.liebertpub.com/doi/10.1089/ten.tec.2015.0375

[51] Weeber F, Van De Wetering M, Hoogstraat M, Dijkstra KK, Krijgsman O, Kuilman T, et al. Preserved genetic diversity in organoids cultured from biopsies of human colorectal cancer metastases. Proc Natl Acad Sci U S A [Internet]. 2015 Oct 27 [cited 2021 Mar 15];112 (43):13308-11. Available https://www.pnas.org/content/112/43/13308

[52] Van De Wetering M, Francies HE, Francis JM, Bounova G, Iorio F, Pronk A, et al. Prospective derivation of a living organoid biobank of colorectal cancer patients. Cell [Internet]. 2015 May 7 [cited 2021 Mar 15];161 (4):933-45. Available http://dx.doi.org/10.1016/j.cell.2015.03.053

from:

[53] Jacob F, Pather SR, Huang WK, Zhang F, Wong SZH, Zhou $\mathrm{H}$, et al. Human Pluripotent Stem Cell-Derived Neural Cells and Brain Organoids Reveal SARS-CoV-2 Neurotropism Predominates in Choroid Plexus Epithelium. Cell Stem Cell [Internet]. 2020;27 (6):937-950.e9. Available from: https://doi.org/10.1016/j.stem.2020.09.016

[54] Duan X, Han Y, Yang L, Nilsson-Payant B, Wang P, Zhang $\mathrm{T}$, et al. Identification of Drugs Blocking SARS-CoV-2 Infection using Human Pluripotent Stem Cell-derived Colonic Organoids. bioRxiv [Internet]. 2020 May 2 [cited 2021 Mar 16];2020.05.02.073320. Available from: https://doi.org/10.1101/2020.05.02.073320

[55] Han Y, Yang L, Duan X, Duan F, Nilsson-Payant B, Yaron $\mathrm{T}$, et al. Identification of Candidate COVID-19 Therapeutics using hPSC-derived Lung Organoids. bioRxiv Prepr Serv Biol [Internet]. 2020 May 5 [cited 2021 Mar 16];2020.05.05.079095. Available from: https://doi.org/10.1101/2020.05.05.079095

[56] Harschnitz O, Studer L. Human stem cell models to study host-virus interactions in the central nervous system. Nat Rev Immunol [Internet]. 2021; Available from https://doi.org/10.1038/s41577-020-00474-y

[57] Daviaud N, Friedel RH, Zou H. Vascularization and engraftment of transplanted human cerebral organoids in mouse cortex. eNeuro. 2018;5 (6):1-18. 
[58] Mansour AA, Gonçalves JT, Bloyd CW, Li H, Fernandes S, Quang D, et al. An in vivo model of functional and vascularized human brain organoids. Nat Biotechnol [Internet]. 2018;36 (5):432-41. Available from: http://dx.doi.org/10.1038/nbt.4127

[59] Phan N, Hong JJ, Tofig B, Mapua M, Elashoff D, Moatamed NA, et al. A simple high-throughput approach identifies actionable drug sensitivities in patient-derived tumor organoids. Commun Biol. 2019;2(1):1-11.

[60] Lo Y-H, Karlsson K, Kuo CJ. Applications of organoids for cancer biology and precision medicine. Nat Cancer [Internet]. 2020;1 (8):761-73. Available from: http://dx.doi.org/10.1038/s43018-020-0102-y

[61] Marton RM, Pașca SP. Organoid and Assembloid Technologies for Investigating Cellular Crosstalk in Human Brain Development and Disease. Trends Cell Biol. 2020;30 (2):133-43.

[62] Lee SH, Hu W, Matulay JT, Silva M V., Owczarek TB, Kim $\mathrm{K}$, et al. Tumor Evolution and Drug Response in Patient-Derived Organoid Models of Bladder Cancer. Cell [Internet]. 2018;173 (2):515-528.e17. Available from: https://doi.org/10.1016/j.cell.2018.03.017

[63] Sachs N, de Ligt J, Kopper O, Gogola E, Bounova G, Weeber F, et al. A Living Biobank of Breast Cancer Organoids Captures Disease Heterogeneity. Cell [Internet]. 2018;172 (1-2):373-386.e10. Available from: https://doi.org/10.1016/j.cell.2017.11.010

[64] Broutier L, Mastrogiovanni G, Verstegen MMA, Francies HE, Gavarró LM, Bradshaw CR, et al. Human primary liver cancer-derived organoid cultures for disease modeling and drug screening. Nat Med [Internet]. 2017;23 (12):1424-35. Available from: http://dx.doi.org/10.1038/nm.4438

[65] Pauli C, Hopkins BD, Prandi D, Shaw R, Fedrizzi T, Sboner $\mathrm{A}$, et al. Personalized in vitro and in vivo cancer models to guide precision medicine. Cancer Discov. 2017;7 (5):46277.

[66] Ganesh K, Wu C, O’Rourke KP, Szeglin BC, Zheng Y, Sauvé CEG, et al. A rectal cancer organoid platform to study individual responses to chemoradiation. Nat Med. 2019;25 (10):1607-14.

[67] Yao Y, Xu X, Yang L, Zhu J, Wan J, Shen L, et al. Patient-Derived Organoids Predict Chemoradiation Responses of Locally Advanced Rectal Cancer. Cell Stem Cell [Internet]. 2020;26 (1):17-26.e6. Available from: https://doi.org/10.1016/j.stem.2019.10.010

[68] Tiriac H, Belleau P, Engle DD, Plenker D, Deschênes A, Somerville TDD, et al. Organoid profiling identifies common responders to chemotherapy in pancreatic cancer. Cancer Discov. 2018;8 (9):1112-29.

[69] Nanki K, Toshimitsu K, Takano A, Fujii M, Shimokawa M, Ohta Y, et al. Divergent Routes toward Wnt and R-spondin Niche Independency during Human Gastric Carcinogenesis. Cell [Internet]. 2018;174 (4):856-869.e17. Available from: https://doi.org/10.1016/j.cell.2018.07.027

[70] Kondo J, Inoue M. Application of Cancer Organoid Model for Drug Screening and Personalized Therapy. Cells. 2019;8 (5):470.

[71] Byrne AT, Alférez DG, Amant F, Annibali D, Arribas J, Biankin A V., et al. Interrogating open issues in cancer precision medicine with patient-derived xenografts. Nat Rev Cancer [Internet]. 2017;17 (4):254-68. Available from: http://dx.doi.org/10.1038/nrc.2016.140

[72] Gao D, Vela I, Sboner A, Iaquinta PJ, Karthaus WR, Gopalan A, et al. Organoid cultures derived from patients with advanced prostate cancer. Cell [Internet]. 2014;159(1):176-87. Available from: http://dx.doi.org/10.1016/j.cell.2014.08.016

[73] Huang L, Holtzinger A, Jagan I, Begora M, Lohse I, Ngai N, et al. Ductal pancreatic cancer modeling and drug screening using human pluripotent stem cell- and patient-derived tumor organoids. Nat Med [Internet]. 2015;21(11):1364-71. Available from: http://dx.doi.org/10.1038/nm.3973

[74] Rückert F, Aust D, Böhme I, Werner K, Brandt A, Diamandis EP, et al. Five primary human pancreatic adenocarcinoma cell lines established by the outgrowth method. J Surg Res. 2012;172 (1):29-39.

[75] Fatehullah A, Tan SH, Barker N. Organoids as an in vitro model of human development and disease. Nat Cell Biol [Internet]. 2016;18 $\quad$ (3):246-54. Available from: http://dx.doi.org/10.1038/ncb3312

[76] Skardal A, Devarasetty M, Rodman C, Atala A, Soker S. Liver-Tumor Hybrid Organoids for Modeling Tumor Growth and Drug Response In Vitro. Ann Biomed Eng. 2015;43 (10):2361-73.

[77] Kaushik G, Ponnusamy MP, Batra SK. Concise Review: Current Status of Three-Dimensional Organoids as Preclinical Models. Stem Cells. 2018;36(9):1329-40.

[78] Mondrinos MJ, Jones PL, Finck CM, Lelkes PI. Engineering de novo assembly of fetal pulmonary organoids. Tissue Eng - Part A. 2014;20(21-22):2892-907.

[79] Soen Y, Mori A, Palmer TD, Brown PO. Exploring the regulation of human neural precursor cell differentiation using arrays of signaling microenvironments. Mol Syst Biol. $2006 ; 2$.

[80] Labarge MA, Nelson CM, Villadsen R, Fridriksdottir A, Ruth JR, Stampfer MR, et al. Human mammary progenitor cell fate decisions are products of interactions with combinatorial microenvironments. Integr Biol. 2009;1 (1):70-9.

[81] Flaim CJ, Chien S, Bhatia SN. An extracellular matrix microarray for probing cellular differentiation. Nat Methods. 2005;2 (2):119-25.

[82] Corrò C, Novellasdemunt L, Li VSW. A brief history of organoids. Am J Physiol - Cell Physiol. 2020;319 (1): C151-65. 